\title{
Impact of Coronary Stent Architecture on Clinical Outcomes: Do Minor Changes in Stent Architecture Really Matter?
}

\author{
Amin Ariff Bin Nuruddin · Wan Azman Wan Ahmad • \\ Matthias Waliszewski - Tay Mok Heang - Liew Houng Bang • \\ Ahmad Khairuddin Mohamed Yusof · Imran Zainal Abidin • \\ Ahmad Syadi Zuhdi · Florian Krackhardt
}

Received: September 30, 2020 / Published online: December 4, 2020

(c) The Author(s) 2020

\section{ABSTRACT}

Introduction: The objective of this study was to compare the accumulated clinical outcomes of two Malaysian all-comers populations, each treated with different polymer-free sirolimuseluting stents (PF-SES) of similar stent design.

Methods: The Malaysian subpopulation of two all-comers observational studies based on the

A. A. B. Nuruddin $(\bowtie) \cdot$ A. K. M. Yusof

National Heart Institute Cardiology Department,

Kuala Lumpur, Malaysia

e-mail: dramin@ijn.com.my

W. A. W. Ahmad

University Malaya Medical Centre, Kuala Lumpur, Malaysia

M. Waliszewski

Medical Scientific Affairs, B. Braun Melsungen AG, Berlin, Germany

M. Waliszewski · F. Krackhardt

Department of Internal Medicine and Cardiology, Charité-Universitätsmedizin Berlin, Campus

Virchow, Berlin, Germany

T. M. Heang

Pantai Hospital Ayer Keroh, Ayer Keroh, Melaka,

Malaysia

L. H. Bang

Hospital Queen Elizabeth II, Kota Kinabalu, Sabah, Malaysia

I. Z. Abidin - A. S. Zuhdi

University Malaya Medical Center, Kuala Lumpur, Malaysia same protocol (ClinicalTrials.gov Identifiers: NCT02629575 and NCT02905214) were combined and compared to a Malaysian-only cohort which was treated with a later-generation PFSES. The PF-SES's used differed only in their bare-metal backbone architecture, with otherwise identical sirolimus coating. The primary endpoint was the accumulated target lesion revascularization (TLR) rate at 12 months. The rates of major adverse cardiac events (MACE), stent thrombosis (ST) and myocardial infarction (MI) were part of the secondary endpoints.

Results: A total of 643 patients were treated with either the first-generation PF-SES (413 patients) or second-generation PF-SES (230 patients). Patient demographics were similar in terms of age $(p=0.744)$, male gender $(0.987)$, diabetes mellitus $(p=0.293)$, hypertension $(p=0.905)$ and acute coronary syndrome (ACS, $44.8 \%$ vs. $46.1 \%, p=0.752$ ) between groups. There were no differences between treatment groups in terms of lesion length $(20.8 \pm 7.3 \mathrm{~mm}$ vs. $22.9 \pm 7.9, p=0.111$ ) or vessel diameter $(2.87 \pm 0.39$ vs. $2.93 \pm 0.40, p=0.052)$ despite numerically smaller diameters in the first-generation PF-SES group. The second-generation PF-SES tended to have more complex lesions as characterized by calcification $(10.3 \%$ vs. $16.2 \%$, $p=0.022)$, severe tortuosity $(3.5 \%$ vs. $6.9 \%$, $p=0.041)$ and $\mathrm{B} 2 / \mathrm{C}$ lesions $(49.2 \%$ vs. $62.8 \%$, $p<0.001)$. The accumulated TLR rates did not differ significantly between the first- and second-generation PF-SES $(0.8 \%$ vs. $0.9 \%$, 
$p=0.891)$. The accumulated MACE rates were not significantly different $(p=0.561)$, at $1.5 \%$ $(6 / 413)$ and $2.2 \%(5 / 230)$, respectively.

Conclusions: Modifications in coronary stent architecture which enhance the radial strength and radiopacity without gross changes in strut thickness and design do not seem to impact clinical outcomes.

Clinical Trial Registration: ClinicalTrials.gov Identifiers: NCT02629575 and NCT02905214.

Keywords: MACE; Polymer-free; Sirolimus; Stent architecture; TLR

\section{Key Summary Points}

Drug-eluting stents (DES) are the standard of care for percutaneous coronary interventions (PCI).

Clinical outcomes after PCI depend also on stent related factors such as stent design and coating.

Procedure related and patient related factors may also affect clinical outcomes.

Radial strength and radio-opacity of DES designs can be improved without gross changes in strut thickness.

These modifications in DES architecture without gross changes in strut thickness do not seem to impact clinical outcomes.

\section{DIGITAL FEATURES}

This article is published with digital features to facilitate understanding of the article. The digital features can be accessed on the article's associated Figshare page. To view digital features for this article go to https://doi.org/10. 6084/m9.figshare.13214918.

\section{INTRODUCTION}

With the new Medical Device Regulation (MDR) being legally binding for all device manufacturers in Europe, there are regulatory changes of paramount importance. According to the MDR, devices are equivalent if they are of similar design and used under similar conditions, and have similar specifications and properties including their physicochemical properties [1]. While this regulatory framework focuses only on stent-related factors, there is a plethora of other patient- or procedure-related factors which impact clinical outcomes (Fig. 1).

The design history of the latest-generation drug-eluting stents (DES) investigated in this study dates back to its early stainless steel predecessor (Coroflex ${ }^{\circledR}$, B. Braun Melsungen AG), which was first launched in 1999. The device was studied by Kalmbach et al. [2] in a singlearm trial with angiographic endpoint revealing a low late lumen loss of $0.64 \pm 0.78 \mathrm{~mm}$. Due to the thin struts of the device, the crossing profile of the crimped section was $<1.00 \mathrm{~mm}$. Further development of this bare metal backbone

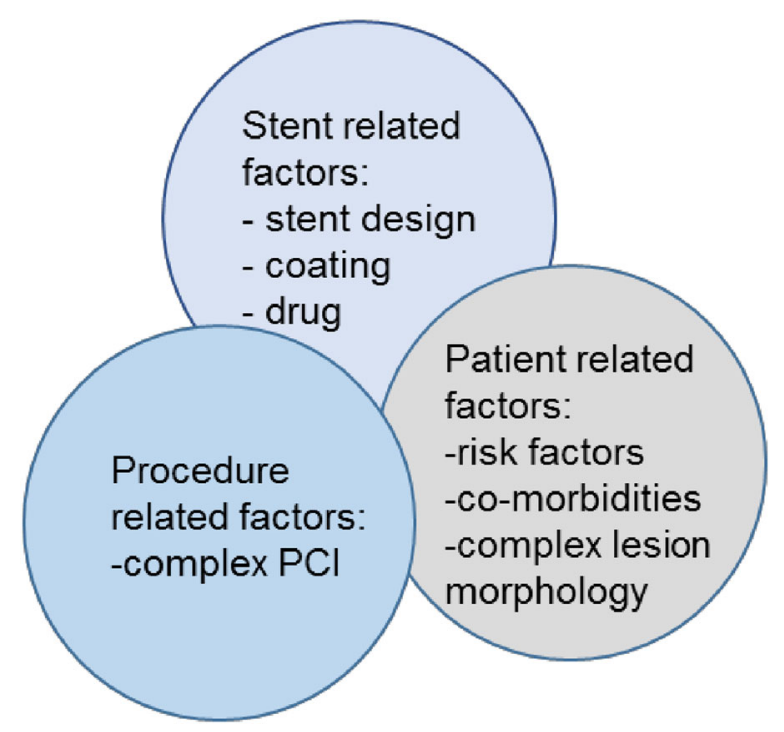

Fig. 1 Factors impacting on clinical outcomes after DES procedures (based on Krackhardt et al. [20]) 
resulted in passive coating with polyphosphazene [3], followed by paclitaxel-polymer coating to transform the BMS backbone into a paclitaxel-eluting stent system [4] similar to the extensively studied Taxus $^{\circledR}$ paclitaxel-eluting stent (PES; Boston Scientific). While still maintaining the original sinusoidal ring elements connected by flexible bridges, the stainless steel platform was changed to cobalt-chromium alloy. This new BMS platform was equally studied in an unselected patient population by Bocksch and coworkers [5] before the clinically proven sirolimus-probucol [6] coating was applied to this stent platform [7].

While there is a paucity of data relating stent design and clinical outcomes, Watson and coworkers [8] addressed the mechanical properties and their potential clinical ramifications. Whereas radial strength, radiopacity and a high stripping force of the crimped stent are associated with more metal, they contribute to an increased overall stiffness. This in turn reduces the deliverability of the stent to the lesion site. To counterbalance shortcomings in lesion crossability, the balloon catheter is typically coated to reduce intra-procedural friction. One key aspect [8] may be the stent's ability to resist longitudinal deformation in case individual stent struts may catch on "roadblocks" in the lesion site. Longitudinal compression may also increase the risk for malapposed stent struts, which are associated with a higher risk of additional stenting and stent thrombosis (ST) [9]. Literature reports [10] have documented the risk of longitudinal compression primarily with stent designs having only two connectors between the ring elements. Another aspect which relates stent design to radial force in left main coronary artery stenting and large sidebranch bifurcations was reported by Noad et al. [11]. They point out that while more ring connectors may increase the longitudinal compression resistance, they may also lead to a higher risk of stent fractures, which are the main culprits for ST [12].

The purpose of this post hoc analysis is to compare the accumulated clinical event rates from two real-word clinical studies, each using a slightly different polymer-free sirolimus-eluting stent (PF-SES) design with an otherwise identical polymer-free sirolimus-coating.

\section{METHODS}

\section{Study Design}

Adult patients were prospectively enrolled in seven Malaysian centers (ClinicalTrials.gov Identifiers NCT02629575, NCT02905214) $[7,13]$, treated with a first-generation PF-SES and compared to a Malaysian all-comers cohort receiving the second-generation PF-SES. All of these studies were based on the same protocol and used the same data capture system (studiesportal.com). A follow-up window of $12 \pm 3$ months was allowed to accommodate for the all-comers nature of this observational study.

\section{Ethics Approval}

Prior to commencing this study, two lead ethics votes were obtained to cover all participating centers (IJN Research Ethics Committee, Kuala Lumpur, nos. IJNREC/142/2016 and IJNREC/04/ 2016; Medical Ethics Committee University of Malaya Medical Center, no. 20166-2540). The Declaration of Helsinki in its most recent form was the basis for this trial. Patients were informed and consented prior to enrollment. No patient was included without prior consent.

\section{Endpoints and Definitions}

The primary endpoint was the accumulated target lesion revascularization rate (TLR, coronary artery bypass grafting and repeat percutaneous coronary intervention [Re-PCI]). The secondary endpoints were the rates of myocardial infarction (MI), all-cause death and major adverse cardiac events (MACE) consisting of TLR, myocardial infarction (MI) and all-cause death [14]. MI was based on the available definition at the time the studies were conducted [15]. The all-cause death rate was used to define the accumulated MACE rate, while cardiac death was only defined during hospitalization. 
Acute/subacute ST was defined by the Academic Research Consortium (ARC) criteria [14]. Minor bleeding was defined as Bleeding Academic Research Consortium (BARC) types 1 and 2, whereas major bleeding episodes were categorized as BARC $3 a-5$ [16]. The criterion for renal insufficiency was an estimated glomerular filtration rate $(\mathrm{eGFR})<60 \mathrm{~mL} / \mathrm{min} / 1.73 \mathrm{~m}^{2}$ and a cutoff eGFR rate for mandatory dialysis of $<15 \mathrm{~mL} / \mathrm{min} / 1.73 \mathrm{~m}^{2}$. Severe vessel tortuosity was defined by the angulation criterion of $>45^{\circ}$ [17].

\section{Materials}

Two ultrathin strut PF-SES's (Coroflex $^{\odot}$ ISAR and Coroflex ${ }^{\odot}$ ISAR NEO, B. Braun Melsungen AG, Germany) were used in this comparative study. Their coating technology, which consists of a probucol-sirolimus matrix on the abluminal side only, was previously described by Krackhardt et al. [7]. The PF-SES's were implanted following each institution's guidelines and preferences. The differences between these two devices were primarily in the slightly modified stent architecture, i.e. ring connectors and slightly widened connector base as shown in Fig. 2, which shows the BMS backbones of the PF-SES's. This stent architecture modification was beneficial for enhancing the radiopacity of the second-generation PF-SES. Moreover, it resulted in a 50\% increase in radial strength.

The two PF-SES's have an identical polymerfree stent coating, which was intensively studied in the ISAR-TEST 5 trial with a 10-year clinical follow-up [6]. The devices were studied in different ethnic subpopulations [18], in lesion morphological subgroups [8] and dialyzed patients [19], and were investigated with a focus on real-world dual-antiplatelet therapy (DAPT) [20].

\section{Inclusion and Exclusion Criteria}

Adult patients had to meet the requirements for PCI at the time the study was conducted [21]. Patients with stable angina and/or objective proof of ischemia or patients with acute

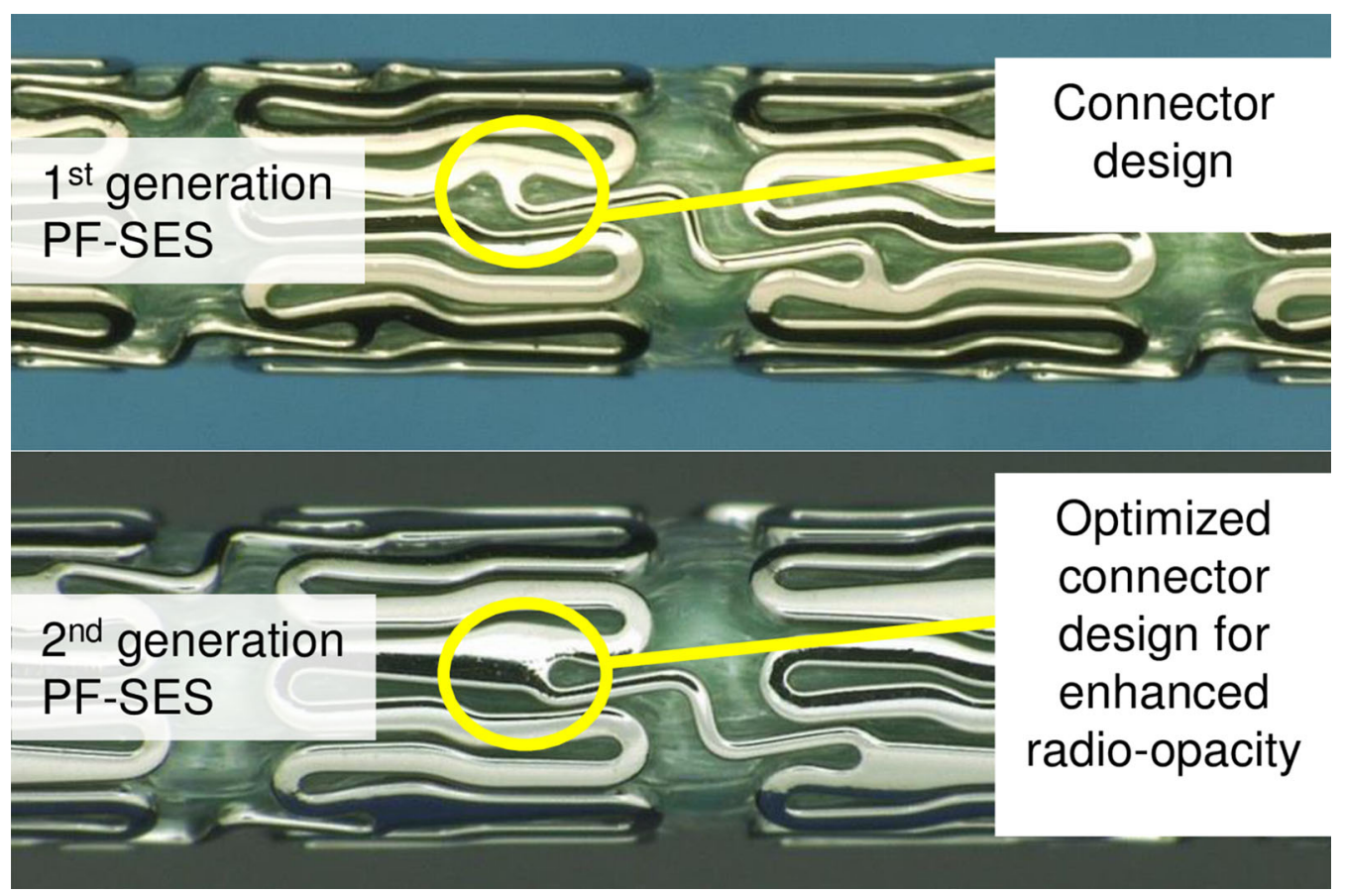

Fig. 2 Comparison of two PF-SES's with differences in stent architecture (top panel: Coroflex ${ }^{\circledR}$ ISAR, bottom panel: Coroflex ${ }^{\circledR}$ ISAR NEO) 
coronary syndrome (ACS) were included. De novo lesions or in-stent restenosis (ISR) in single or multiple vessel disease with reference diameters from 2.0 to $4.0 \mathrm{~mm}$ could be treated.

\section{Procedural Approach}

Radial or femoral vascular access was recommended with an introducer sheath of at least 5 French in diameter. The operators could predilate lesions with a balloon catheter of their preference. Alternatively, the direct stenting approach could also be chosen. All patients received intravenous administration of heparin (70 IU/kg), which was supplemented as needed. Preloading with platelet aggregation inhibitor was recommended but not mandatory.

\section{Post-Procedural Medication}

The choice of the P2Y12 receptor antagonists (clopidogrel, prasugrel, ticagrelor) was left to the discretion of the treating physician. Various post-procedural anti-platelet therapy regimens, including clopidogrel $75 \mathrm{mg} /$ day, prasugrel $10 \mathrm{mg} /$ day or ticagrelor $2 \times 90 \mathrm{mg} /$ day, were allowed, with lifetime administration of acetylsalicylic acid 100-325 mg/day [21].

\section{Data Collection}

An electronic data capture system [22, 23] with a proven track record was used for both cohorts. The system enabled built-in plausibility checks during each stage of the data entry. In the case of discrepancies, as detected by remote monitoring, a data verification process was initiated to ensure the accuracy of the collected data.

\section{Statistical Analysis}

To evaluate dichotomous and categorical variables, the two-sided Fisher's exact test or the chi-square statistic were used whenever applicable. Means and standard deviations were used to describe continuous variables, which were compared with the unpaired $t$ test or the Mann-Whitney $U$ test in cases where the
Shapiro-Wilk test revealed a strong deviation from a normal distribution. The significance level $\alpha$ was 0.05 for all tests. SPSS version 24.0 software (IBM Corp., Armonk, NY) was used for all statistical analyses.

\section{Results}

\section{Baseline Data}

In the entire cohort, 643 patients (Table 1) were treated with either the first-generation PF-SES (413 patients) or the second-generation PF-SES (230 patients). Recruitment of the individual studies occurred from November 2014 to December 2018. Patient demographics were quite similar overall in terms of age $(59.7 \pm 10.9$ years vs. $60.0 \pm 11.3, p=0.744)$, male gender ( $81.6 \%$ vs. $81.3 \%, p=0.987)$, diabetes mellitus $(51.3 \%$ vs. $55.7 \%, p=0.293)$, hypertension $(63.4 \%$ vs. $63.9 \%, p=0.905)$ and ACS rates $(44.8 \%$ vs. $46.1, p=0.752)$.

Regarding the lesion morphological baseline data, there were no differences between treatment groups in terms of lesion length $(20.8 \pm 7.3 \mathrm{~mm}$ vs. $22.9 \pm 7.9, p=0.111)$ or vessel diameter $(2.87 \pm 0.39$ vs. $2.93 \pm 0.40$, $p=0.052$ ) despite numerically smaller diameters in the first-generation PF-SES group (Table 1). Patients treated with second-generation PF-SES tended to have more complex lesions as characterized by calcification $(10.3 \%$ vs. $16.2 \%, p=0.022)$, severe tortuosity ( $3.5 \%$ vs. $6.9 \%, p=0.041)$ and $\mathrm{B} 2 / \mathrm{C}$ lesions $(49.2 \%$ vs. $62.8 \%, p<0.001)$.

\section{Procedural Details}

Pre-dilatation was carried out in $87.8 \%$ of the overall cohort (Table 2), whereas post-dilatation was conducted in $72.2 \%$. All pre- and post-dilatation was done with non-compliant balloons at the discretion of the operator. Cutting/scoring balloons was not recommended or used to prepare the lesions. Rotablation devices were permitted but not used. Stent diameters were slightly larger in the second-generation PF-SES group $(2.92 \pm 0.39 \mathrm{~mm}$ vs. $2.86 \pm 0.39 \mathrm{~mm}$, $p=0.046)$, while stent lengths were comparable 
Table 1 Patient demographics, lesion and procedural details

\begin{tabular}{|c|c|c|c|c|}
\hline Variable & All patients & First-generation PF-SES & Second-generation PF-SES & $P$ value \\
\hline Patients & 643 & 413 & 230 & - \\
\hline Lesions & 731 & 484 & 247 & - \\
\hline Devices & 787 & 528 & 259 & - \\
\hline Age (years) & $59.8 \pm 11.1$ & $59.7 \pm 10.9$ & $60.0 \pm 11.3$ & 0.744 \\
\hline Male gender & $523(81.3 \%)$ & $336(81.6 \%)$ & $187(81.3 \%)$ & 0.987 \\
\hline Diabetes & $340(52.9 \%)$ & $212(51.3 \%)$ & $128(55.7 \%)$ & 0.293 \\
\hline Hypertension & $409(63.6 \%)$ & $262(63.4 \%)$ & $147(63.9 \%)$ & 0.905 \\
\hline Renal insufficiency & $51(7.9 \%)$ & $23(5.6 \%)$ & $28(12.2 \%)$ & 0.003 \\
\hline Dialysis dependence & $21(3.3 \%)$ & $13(3.1 \%)$ & $8(3.5 \%)$ & 0.821 \\
\hline ACS & $291(45.3 \%)$ & $185(44.8 \%)$ & $106(46.1 \%)$ & 0.752 \\
\hline \multicolumn{5}{|l|}{ Target vessel } \\
\hline LAD & $369(50.5 \%)$ & $242(50.0 \%)$ & $127(51.4 \%)$ & 0.440 \\
\hline $\mathrm{CX}$ & $168(23.0 \%)$ & $116(24.0 \%)$ & $352(21.1 \%)$ & \\
\hline $\mathrm{RCA}$ & $193(26.4 \%)$ & $126(26.0 \%)$ & $67(27.1 \%)$ & \\
\hline Graft & $1(0.1 \%)$ & $0(0.0 \%)$ & $1(0.4 \%)$ & \\
\hline Thrombotic occlusion & $69(9.4 \%)$ & $39(8.1 \%)$ & $30(12.1 \%)$ & 0.074 \\
\hline Diffuse vessel disease & $263(36.0 \%)$ & $174(36.0 \%)$ & $89(36.0 \%)$ & 0.983 \\
\hline Calcification & $90(12.3 \%)$ & $50(10.3 \%)$ & $40(16.2 \%)$ & 0.022 \\
\hline Ostial lesion & $61(8.3 \%)$ & $45(9.3 \%)$ & $16(6.5 \%)$ & 0.192 \\
\hline Bifurcations & $47(6.4 \%)$ & $26(5.4 \%)$ & $21(8.5 \%)$ & 0.103 \\
\hline Severe tortuosity & $34(4.7 \%)$ & $17(3.5 \%)$ & $17(6.9 \%)$ & 0.041 \\
\hline In-stent restenosis & $13(1.8 \%)$ & $7(1.4 \%)$ & $6(2.4 \%)$ & 0.342 \\
\hline AHA/ACC type B2/C lesion & $393(53.8 \%)$ & $238(49.2 \%)$ & $155(62.8 \%)$ & $<0.001$ \\
\hline Reference diameter (mm) & $2.89 \pm 0.40$ & $2.87 \pm 0.39$ & $2.93 \pm 0.40$ & 0.052 \\
\hline Lesion length & $22.3 \pm 7.6$ & $20.8 \pm 7.3$ & $22.9 \pm 7.9$ & 0.111 \\
\hline Degree of stenosis (\%) & $84.0 \pm 10.4$ & $84.1 \pm 10.4$ & $84.0 \pm 10.4$ & 0.981 \\
\hline Pre-dilation & $642(87.8 \%)$ & $417(86.2 \%)$ & $225(91.1 \%)$ & 0.054 \\
\hline Post-dilatation & $528(72.2 \%)$ & $339(70.0 \%)$ & $189(76.5 \%)$ & 0.064 \\
\hline DES per patient & $1.22 \pm 0.51$ & $1.26 \pm 0.55$ & $1.13 \pm 0.43$ & 0.003 \\
\hline DES diameter (mm) & $2.88 \pm 0.39$ & $2.86 \pm 0.39$ & $2.92 \pm 0.39$ & 0.046 \\
\hline DES length $(\mathrm{mm})$ & $23.8 \pm 7.3$ & $23.7 \pm 7.2$ & $24.0 \pm 7.4$ & 0.633 \\
\hline DES inflation pressure (atm) & $13.6 \pm 2.9$ & $13.9 \pm 2.9$ & $13.1 \pm 2.8$ & $<0.001$ \\
\hline
\end{tabular}


Table 1 continued

\begin{tabular}{lllll}
\hline Variable & All patients & First-generation PF-SES & Second-generation PF-SES & $\boldsymbol{P}$ value \\
\hline Final result \% stenosis & $0.6 \pm 2.9$ & $0.5 \pm 2.7$ & $0.7 \pm 3.2$ & 0.488 \\
Overall technical success per stent & $725(99.2 \%)$ & $478(98.8 \%)$ & $247(100.0 \%)$ & 0.079 \\
\hline
\end{tabular}

$A C S$ acute coronary syndrome, $D E S$ drug-eluting stent, $L A D$ left anterior descending artery, $C X$ circumflex artery, $R C A$ right coronary artery, $A H A / A C C$ American Heart Association/American College of Cardiology

$(23.7 \pm 7.2 \mathrm{~mm}$ vs. $24.0 \pm 7.4 \mathrm{~mm}, p=0.633)$. Inflation pressures were higher in the first-generation PF-SES group $(13.9 \pm 2.9 \mathrm{~atm}$ vs. $13.1 \pm 2.8 \mathrm{~atm}, p<0.001)$. There were no differences in terms of the overall technical success rate per stent implantation despite a numerically higher rate in the second-generation PFSES group $(98.8 \%$ vs. $100.0 \%, p=0.079)$.

\section{Co-medication}

Clopidogrel was preferred (Table 2) for preloading and post-procedural anti-platelet therapy. There were significant differences in terms of DAPT regimens between the two treatment groups. The decreasing use of ticagrelor in ACS patients with second-generation PF-SES is noteworthy.

As previously reported by Krackhardt et al. [18], independent of the patients' presentation at baseline, the DAPT duration in Malaysia is close to 12 months, with $11.6 \pm 1.7$ months for first-generation PF-SES versus $11.9 \pm 1.0$ months $(p=0.045)$ for the secondgeneration PF-SES.

\section{Clinical Results}

At the 12-month follow-up, 643 patients were available for analysis (96.1\%). The overall rates for accumulated TLR were not significantly different between first- and second-generation PFSES $(0.8 \%$ vs. $0.9 \%, p=0.891)$. The accumulated MACE rates were not different $(p=0.561)$, with $1.5 \%(6 / 413)$ and $2.2 \%(5 / 230)$, respectively. The rates for accumulated definite/probable ST were not significantly different $(p=0.065)$, and bleeding complications were also not different between the treatment groups $(0.5 \%$ vs. $0.4 \%$, $p=0.894)$. Subgroup analyses in B2/C and ACS patients were conducted for comparison. In ACS patients there were no differences in terms of 12 -month MACE (3.0\% vs. $1.9 \%, p=0.591)$. Likewise in patients with B2/C lesions, the accumulated MACE rates did not differ $(2.7 \%$ vs. $2.1 \%, p=0.699)$.

\section{DISCUSSION}

Although it is conceivable to strictly regulate device modifications prior to market approval, the significance of design changes and their need for clinical evidence needs to be reasonable. While the second-generation PF-SES had numerically higher rates of technical success in crossing the lesion as compared to the firstgeneration PF-SES, its radiopacity and radial force were increased based on preclinical testing. The increase in radial force to become clinically relevant was confirmed with the significantly lower inflation pressure in the second-generation PF-SES, i.e. a lower pressure was necessary to plastically deform the stent so that recoil could be adequately addressed. Despite the small absolute difference, this finding remains significant.

Within the framework of observational statistics, we could not detect differences in clinical outcomes between the two cohorts. Nevertheless, we need to point out that the event rates were quite low, with an overall MACE rate of $1.8 \%$, which makes it difficult to conduct a properly powered randomized controlled trial. One reason for these low event rates may be the 12-month DAPT recommendation in Malaysia even in stable coronary artery disease patients [18]. However, due to the observational character of this study, event 
Table 2 Peri-procedural drug therapy and recommended DAPT regimens

\begin{tabular}{|c|c|c|c|c|c|}
\hline Drug type & Drug & $\begin{array}{l}\text { All } \\
\text { patients }\end{array}$ & $\begin{array}{l}\text { First-generation } \\
\text { PF-SES }\end{array}$ & $\begin{array}{l}\text { Second-generation } \\
\text { PF-SES }\end{array}$ & $p$ value \\
\hline Patients & & 643 & 413 & 230 & - \\
\hline Pre-PCI & Clopidogrel & $312(48.5 \%)$ & $202(48.9 \%)$ & $110(47.8 \%)$ & $<0.001$ \\
\hline \multicolumn{6}{|l|}{$\begin{array}{l}\text { Anti-platelet } \\
\text { therapy (APT) }\end{array}$} \\
\hline & Ticagrelor & $37(5.8 \%)$ & $37(9.0 \%)$ & $0(0.0 \%)$ & \\
\hline & Prasugrel & $9(1.4 \%)$ & $2(0.5 \%)$ & $7(3.0 \%)$ & \\
\hline & Aspirin only & $5(0.8 \%)$ & $4(1.0 \%)$ & $1(0.4 \%)$ & \\
\hline & Ticlopidine & $2(0.3 \%)$ & $2(0.5 \%)$ & $0(0.0 \%)$ & \\
\hline & No preloading & $278(12.0 \%)$ & $166(40.2 \%)$ & $112(48.7 \%)$ & \\
\hline Post-PCI & Clopidogrel & $464(72.2 \%)$ & $292(70.7 \%)$ & $172(74.8 \%)$ & $<0.001$ \\
\hline \multicolumn{6}{|l|}{$\begin{array}{l}\text { Anti-platelet } \\
\text { therapy (APT) }\end{array}$} \\
\hline & Ticagrelor & $148(23.0 \%)$ & $102(24.7 \%)$ & $46(20.0 \%)$ & \\
\hline & Prasugrel & $4(0.6 \%)$ & $4(1.0 \%)$ & $0(0.0 \%)$ & \\
\hline & Aspirin only & $15(2.3 \%)$ & $3(0.7 \%)$ & $12(5.2 \%)$ & \\
\hline & Unknown & $12(1.9 \%)$ & $12(2.9 \%)$ & $0(0.0 \%)$ & \\
\hline Triple therapy & $\begin{array}{l}\mathrm{DAPT}+\text { vitamin } \mathrm{K} \\
\text { antagonist or NOAC }\end{array}$ & $0(0.0 \%)$ & $0(0.0 \%)$ & $0(0.0 \%)$ & - \\
\hline Patients with follow-up & & $618(96.1 \%)$ & $389(94.2 \%)$ & $229(99.6 \%)$ & 0.001 \\
\hline $\begin{array}{l}\text { DAPT duration } \\
\text { in months }\end{array}$ & & $11.7 \pm 1.5$ & $11.6 \pm 1.7$ & $11.9 \pm 1.0$ & 0.045 \\
\hline 1 month & & $3(0.5 \%)$ & $3(0.7 \%)$ & $0(0.0 \%)$ & 0.153 \\
\hline $2-3$ months & & $3(0.5 \%)$ & $2(0.5 \%)$ & $1(0.4 \%)$ & \\
\hline 4-6 months & & $1(0.2 \%)$ & $0(0.0 \%)$ & $1(0.4 \%)$ & \\
\hline 6 months & & $19(3.0 \%)$ & $16(3.9 \%)$ & $3(1.3 \%)$ & \\
\hline$>6$ to 12 months & & $1(0.2 \%)$ & $1(0.3 \%)$ & $0(0.0 \%)$ & \\
\hline 12 months & & $588(95.6 \%)$ & $363(94.3 \%)$ & $225(97.8 \%)$ & \\
\hline Unknown status & & $29(4.5 \%)$ & $29(7.0 \%)$ & $0(0.0 \%)$ & \\
\hline
\end{tabular}

underreporting may have occurred equally in both groups, which would still allow a comparison of these two stent generations. To better compare the two treatment groups, subgroup analyses in patients with B2/C lesions and ACS patients were in the 2-3\% range, which also appears somewhat low in the real-world setting.

One alternative analysis to overcome this statistical dilemma is the use of propensity score (PS) matching, which was recently used to study 
the effect of a stent coating in otherwise identical stent platforms. Krackhardt and co-workers [24] studied a PF-SES and compared the clinical results to those of its bare-metal stent analogue. The study revealed the efficacy of the stent coating (reduction in MACE by $5.5 \%$, $p=0.001)$, and the ST rate was also lower in the PF-SES group. Kereiakes and coworkers [25] also used PS matching to compare cohorts, which were treated with the Taxus Liberté paclitaxeleluting stent (PES) or the ION PES. The two PES's used similar drugs and polymer release technologies but differed in stent designs, strut thickness and materials (stainless steel vs. platinum chromium). The study revealed that the second-generation PES with thinner struts was associated with a lower 12-month MACE rate as compared to the first-generation PES (7.5\% vs. $12.0 \%, p=0.007)$. Since earlier DES platforms always used a polymer matrix for drug release over weeks and months, a strong relationship between stent architecture and polymer coating homogeneity was postulated that may have favored the second-generation PES in this study. In bench tests, Guérin and coworkers reported polymer coating damage of earlier-generation DES in a bifurcation model, which may explain their higher stent thrombosis rates [26]. Furthermore, this post hoc comparison by Kereiakes et al. used fundamentally different bare metal backbones, which may have led to the significant difference in MACE that we did not observe in our analysis (Table 3 ).

The comprehensive technical review by Watson et al. [8] stressed the fact that the lesion must be uniformly scaffolded, while sidebranch access should not be compromised. This means that fundamentally different stent designs with varying cell opening diameters and expansion properties have to be clinically tested. If, however, the basic stent design remains the same, as is the case with the two PF-SES's

Table 3 Accumulated clinical outcomes

\begin{tabular}{|c|c|c|c|c|}
\hline Variable & $\begin{array}{l}\text { All } \\
\text { patients }\end{array}$ & $\begin{array}{l}\text { First-generation PF- } \\
\text { SES }\end{array}$ & $\begin{array}{l}\text { Second-generation PF- } \\
\text { SES }\end{array}$ & $\begin{array}{l}p \\
\text { value }\end{array}$ \\
\hline Number of patients & 643 & 413 & 230 & - \\
\hline $\begin{array}{l}\text { Patients with clinical long-term follow-up or early } \\
\text { event }\end{array}$ & $\begin{array}{l}618 \\
\quad(96.1 \%)\end{array}$ & $389(94.2 \%)$ & $229(99.6 \%)$ & 0.001 \\
\hline Time to discharge (days) & $1.6 \pm 4.3$ & $1.5 \pm 2.5$ & $1.6 \pm 6.4$ & 0.861 \\
\hline DAPT duration in months & $11.7 \pm 1.5$ & $11.6 \pm 1.7$ & $11.9 \pm 1.0$ & 0.045 \\
\hline Accumulated MACE & $11(1.8 \%)$ & $6(1.5 \%)$ & $5(2.2 \%)$ & 0.561 \\
\hline Accumulated TLR & $5(0.8 \%)$ & $3(0.8 \%)$ & $2(0.9 \%)$ & 0.891 \\
\hline Re-PCI & $5(0.8 \%)$ & $3(0.8 \%)$ & $2(0.9 \%)$ & 0.891 \\
\hline CABG & $0(0.0 \%)$ & $0(0.0 \%)$ & $0(0.0 \%)$ & - \\
\hline Accumulated MI & $3(0.5 \%)$ & $1(0.3 \%)$ & $2(0.9 \%)$ & 0.287 \\
\hline Accumulated death all causes & $7(1.1 \%)$ & $3(0.8 \%)$ & $4(1.7 \%)$ & 0.268 \\
\hline Accumulated definite/ probable stent thrombosis & $2(0.3 \%)$ & $0(0.0 \%)$ & $2(0.9 \%)$ & 0.065 \\
\hline Acute stent thrombosis, $\leq 24 \mathrm{~h}$ & $0(0.0 \%)$ & $0(0.0 \%)$ & $0(0.0 \%)$ & 0.065 \\
\hline Subacute stent thrombosis, 1-30 days & $0(0.0 \%)$ & $0(0.0 \%)$ & $0(0.0 \%)$ & \\
\hline Late stent thrombosis, $\geq 30$ days & $2(0.3 \%)$ & $0(0.0 \%)$ & $2(0.9 \%)$ & \\
\hline Bleeding complications (minor, major) & $3(0.5 \%)$ & $2(0.5 \%)$ & $1(0.4 \%)$ & 0.894 \\
\hline
\end{tabular}


investigated in this study, the analogy principle ought to be applied to avoid unnecessarily large clinical endpoint trials with a meager expectation of showing non-inferiority for regulatory purposes. Moreover, our results may suggest a 'bridging study' character of our analysis, i.e. data collected with the first-generation PF-SES may also be applicable for the second-generation PF-SES.

\section{Bias and Data Quality}

All-comers cohorts have potential sources of bias. Most importantly, there are operators' preferences the learning curves for a particular device given that we compared with a historic control arm. Event underreporting may also cause bias. However, these unselected patient populations are, from our point of view, the only avenue that may document the efficacy and safety in real-world clinical practice. Finally, the purpose of our comparisons is descriptive in nature, and no formal sample size estimations were carried out.

\section{Limitations}

Observational studies in unselected patients provide community-level data which may not have the same rigor in answering specific questions. Therefore, event underreporting, realworld DAPT modifications and mostly singlelesion PCI may have occurred and significantly contributed to the low event rates which are only useful for comparison between the device generations. It would also have been desirable to document other co-medication such as angiotensin-converting enzyme (ACE) inhibitors, beta blockers, calcium channel blockers and statins. Additionally, intravascular imaging (IVUS, OCT) was not available under routine clinical use in the participating centers due to a lack of reimbursement. This would have helped to determine the radial calcium distribution within the coronary wall to better evaluate the need and type of device for lesion pretreatment.

Furthermore, in the multiethnic population consisting of Malay, Chinese and Indian subpopulations, it would have been highly desirable to further illuminate their respective outcomes.

\section{CONCLUSIONS}

Modifications in coronary stent architecture which enhance radial strength and radiopacity without gross changes in strut thickness do not seem to impact clinical outcomes in a Malaysian unselected patient population.

\section{ACKNOWLEDGEMENTS}

We thank the participants of the study. We also wish to acknowledge the following Medical Affairs Team members who provided regulatory and logistic support to conduct this study: Mr. Denny Herberger (Germany) and Ms. Zoey Hooi (Malaysia). In addition, we are grateful for the engineering insights of Dr. Jorge Calisse and his R\&D Team (Andreas Stolle, Henning Woebken and Dr. Karl Scharschmidt) during the development phases of both PF-SES generations.

Funding. B. Braun Melsungen AG funded the Journal's Rapid Service Fee and the study with an unrestricted research grant. All authors had full access to all of the data in this study, contributed to the identification of the relevant literature, and were involved during all stages of the publication process to ensure the accuracy of the data analysis.

Authorship. All named authors meet the International Committee of Medical Journal Editors criteria for the authorship of this publication. The responsibility to assure the integrity of this entire research work is shared equally by all authors, who gave their approval to publish the finalized article.

Disclosures. Florian Krackhardt is a consultant for B. Braun Melsungen AG. Matthias Waliszewski is full-time employees (Medical Scientific Affairs, B. Braun Melsungen AG) when the manuscript was prepared. Amin Ariff Bin Nuruddin, Wan Azman Wan Ahmad, Tay Mok Heang, Liew Houng Bang, Ahmad Khairuddin 
Mohamed Yusof, Imran Zainal Abidin and Ahmad Syadi Zuhdi have nothing to disclose.

Compliance with ethics guidelines. Prior to commencing this study, two lead ethics votes were obtained to cover all participating centers (IJN Research Ethics Committee, Kuala Lumpur nos. IJNREC/142/2016 and IJNREC/04/2016; Medical Ethics Committee University of Malaya Medical Center no. 20166-2540). The Declaration of Helsinki in its most recent form was the basis for this trial. Patients were informed and consented prior to enrolment. No patient was included without prior consent.

Data availability. The datasets generated during and/or analyzed during the current study are not publicly available to researchers outside of the group of investigators due to proprietary constraints and data protection constraints.

Open Access. This article is licensed under a Creative Commons Attribution-NonCommercial 4.0 International License, which permits any non-commercial use, sharing, adaptation, distribution and reproduction in any medium or format, as long as you give appropriate credit to the original author(s) and the source, provide a link to the Creative Commons licence, and indicate if changes were made. The images or other third party material in this article are included in the article's Creative Commons licence, unless indicated otherwise in a credit line to the material. If material is not included in the article's Creative Commons licence and your intended use is not permitted by statutory regulation or exceeds the permitted use, you will need to obtain permission directly from the copyright holder. To view a copy of this licence, visit http://creativecommons.org/licenses/by$\mathrm{nc} / 4.0 /$.

\section{REFERENCES}

1. Medical Device Coordination Group Document MDCG 2020-5: Clinical Evaluation - Equivalence: A guide for manufacturers and notified bodies, 2020 .
2. Kalmbach C, Rutsch W, Figulla HR. Clinical and angiographic results with the Coroflex Coronary Stent System. J Interv Cardiol. 2002;15(5):363-9.

3. Unverdorben M, Degenhardt R, Sick P, Kastrati A, Desmet W, et al. Evaluation of the Coroflex ThecaStent for reduction of restenosis (ECORI). J Invasive Cardiol. 2005;17(4):199-202.

4. Wiemer M, Degenhardt R, Vallbracht C, Horstkotte $\mathrm{D}$, Schneider $\mathrm{H}$, et al. PECOPS II Investigators. The paclitaxel-eluting Coroflex stent study II (PECOPS II) acute and 6-month clinical and angiographic follow-up, 1-year clinical follow-up. J Interv Cardiol. 2010;23(2):160-6.

5. Bocksch W, Pomar F, Dziarmaga M, Tresukosol D, Ismail $\mathrm{O}$, et al. Coroflex Blue Registry Investigators. Clinical safety and efficacy of a novel thin-strut cobalt-chromium coronary stent system: results of the real world Coroflex Blue Registry. Catheter Cardiovasc Interv. 2010;75(1):78-85.

6. Kufner S, Ernst M, Cassese S, Joner M, Mayer K, Colleran R, et al. ISAR-TEST-5 Investigators. 10-Year Outcomes From a Randomized Trial of PolymerFree Versus Durable Polymer Drug-Eluting Coronary Stents. J Am Coll Cardiol. 2020;76(2):146-58.

7. Krackhardt F, Kočka V, Waliszewski MW, Utech A, Lustermann M, Hudec $M$, et al. Polymer-free sirolimus-eluting stents in a large-scale all-comers population. Open Heart. 2017;4:e000592.

8. Watson T, Webster MW, Ormiston JA, Ruygrok PN, Stewart JT. Long and short of optimal stent design. Open Heart. 2017;4(2):e000680. https://doi.org/10. 1136/openhrt-2017-000680.eCollection2017.

9. Leone AM, Rebuzzi AG, Burzotta F, De Maria GL, Gardi A, Basile E, et al. Stent malapposition, strut coverage and atherothrombotic prolapse after percutaneous coronary interventions in ST-segment elevation myocardial infarction. J Cardiovasc Med (Hagerstown). 2019;20(3):122-30.

10. Vijayvergiya R, Kumar A, Shrivastava S, Kamana NK. Longitudinal stent compression of everolimuseluting stent: A report of 2 cases. World J Cardiol. 2013;5(8):313-6. https://doi.org/10.4330/wjc.v5.i8. 313.

11. Noad RL, Hanratty CG, Walsh SJ. Clinical Impact of Stent Design. Interv Cardiol. 2014;9(2):89-93. https://doi.org/10.15420/icr.2011.9.2.89.

12. Carroll JD. Coronary stent fracture: the hidden truth of a problem more common than stent thrombosis. Catheter Cardiovasc Interv. 2009;73(1):88-9. https://doi.org/10.1002/ccd. 21905. 
13. Krackhardt F, Kočka V, Waliszewski M, Toušek $P$, Janek B, Trenčan $M$, et al. Unrestricted use of polymer-free sirolimus eluting stents in routine clinical practice. Medicine (Baltimore). 2020;99(8): e19119.

14. Cutlip DE, Windecker S, Mehran R, Boam A, Cohen DJ, van Es GA, et al. Clinical end points in coronary stent trials: a case for standardized definitions. Circulation. 2007;115:2344-51.

15. Thygesen K, Alpert JS, Jaffe AS, Simoons ML, Chaitman BR, White HD; Joint ESC/ACCF/AHA/ WHF Task Force for Universal Definition of Myocardial Infarction; Authors/Task Force Members Chairpersons, Thygesen $\mathrm{K}$, Alpert JS, White HD; Biomarker Subcommittee, Jaffe AS, Katus HA, Apple FS, Lindahl B, Morrow DA; ECG Subcommittee, Chaitman BR, Clemmensen PM, Johanson $\mathrm{P}$, Hod $\mathrm{H}$; Imaging Subcommittee, Underwood $\mathrm{R}$, Bax JJ, Bonow JJ, Pinto F, Gibbons RJ; Classification Subcommittee, Fox KA, Atar D, Newby LK, Galvani M, Hamm CW; Intervention Subcommittee, Uretsky BF, Steg PG, Wijns W, Bassand JP, Menasche P, Ravkilde J; Trials \& Registries Subcommittee, Ohman EM, Antman EM, Wallentin LC, Armstrong PW, Simoons ML; Trials \& Registries Subcommittee, Januzzi JL, Nieminen MS, Gheorghiade M, Filippatos G; Trials \& Registries Subcommittee, Luepker RV, Fortmann SP, Rosamond WD, Levy D, Wood D; Trials \& Registries Subcommittee, Smith SC, Hu D, Lopez-Sendon JL, Robertson RM, Weaver D, Tendera M, Bove AA, Parkhomenko AN, Vasilieva EJ, Mendis S; ESC Committee for Practice Guidelines (CPG), Bax JJ, Baumgartner H, Ceconi C, Dean V, Deaton C, Fagard R, Funck-Brentano C, Hasdai D, Hoes A, Kirchhof P, Knuuti J, Kolh P, McDonagh T, Moulin C, Popescu BA, Reiner Z, Sechtem U, Sirnes PA, Tendera M, Torbicki A, Vahanian A, Windecker S; Document Reviewers, Morais J, Aguiar C, Almahmeed W, Arnar DO, Barili F, Bloch KD, Bolger AF, Botker HE, Bozkurt B, Bugiardini R, Cannon C, de Lemos J, Eberli FR, Escobar E, Hlatky M, James S, Kern KB, Moliterno DJ, Mueller C, Neskovic AN, Pieske BM, Schulman SP, Storey RF, Taubert KA, Vranckx P, Wagner DR. Third universal definition of myocardial infarction. J Am Coll Cardiol. 2012;60(16):1581-98. https://doi.org/10.1016/j. jacc.2012.08.001.

16. Mehran R, Rao SV, Bhatt DL, Gibson CM, Caixeta A, Eikelboom J, et al. Standardized bleeding definitions for cardiovascular clinical trials. Circulation. 2011;123:2736-47.

17. Turgut O, Yilmaz A, Yalta K, Yilmaz BM, Ozyol A, Kendirlioglu $\mathrm{O}$, et al. Tortuosity of coronary arteries: An indicator for impaired left ventricular relaxation? Int J Cardiovasc Imaging. 2007;23: 671-7.
18. Krackhardt F, Waliszewski M, Wan Ahmad WA, Kočka V, Toušek P, Janek B, et al. Polymer-free sirolimus-eluting stent use in Europe and Asia: Ethnic differences in demographics and clinical outcomes. PLoS One. 2020;15(1):e0226606.

19. Krackhardt F, Waliszewski MW, Kherad B, Barth C, Marcelli D. Clinical outcomes following polymerfree sirolimus-eluting stent implantations in unselected patients: A descriptive subgroup analysis in patients with renal impairment. Medicine (Baltimore). 2020;99(29):e21244. https://doi.org/10. 1097/MD.0000000000021244.

20. Krackhardt F, Waliszewski M, Kočka V, Toušek P, Janek B, Hudec M, et al. Real-World Dual Antiplatelet Therapy Following Polymer-Free SirolimusEluting Stent Implantations to Treat Coronary Artery Disease. Cardiovasc Drugs Ther. 2020;34(3): 335-44. https://doi.org/10.1007/s10557-02006963-5.

21. Windecker S, Kolh P, Alfonso F, Collet JP, Cremer J, Falk V, et al. 2014 ESC/EACTS Guidelines on myocardial revascularization: The Task Force on Myocardial Revascularization of the European Society of Cardiology (ESC) and the European Association for Cardio-Thoracic Surgery (EACTS) Developed with the special contribution of the European Association of Percutaneous Cardiovascular Interventions (EAPCI). Eur Heart J. 2014;35: 2541-619. https://doi.org/10.1093/eurheartj/ ehu278.

22. Wöhrle J, Zadura M, Möbius-Winkler S, Leschke M, Opitz C, Ahmed W, et al. SeQuentPlease World Wide Registry: clinical results of SeQuent please paclitaxel-coated balloon angioplasty in a largescale, prospective registry study. J Am Coll Cardiol. 2012;60:1733-8. https://doi.org/10.1016/j.jacc. 2012.07.040.

23. Leschke $M$, Waliszewski $M$, Pons $M$, Champin S, Nait Saidi L, Mok Heang T, et al. A Thin strut bare metal stents in patients with atrial fibrillation: Is there still a need for BMS? Catheter Cardiovasc Interv. 2016;88:358-66. https://doi.org/10.1002/ ccd.26261.

24. Krackhardt F, Rosli MA, Leschke M, Schneider A, Sperling C, Heang TM, et al. Propensity score matched all comers population treated with ultra-thin strut bare metal and sirolimus-probucol coated drug-eluting stents of identical stent architecture. Catheter Cardiovasc Interv. 2018;91:1221-8. https://doi.org/10.1002/ccd. 27306. 
25. Kereiakes DJ, Cannon LA, Ormiston JA, Turco MA, Mann T, et al. Propensity-matched patient-level comparison of the TAXUS Liberte and TAXUS element (ION) paclitaxel-eluting stents. Am J Cardiol. 2011;108(6):828-37.
26. Guérin $P$, Pilet $P$, Finet $G$, Gouëffic $Y, N^{\prime}$ Guyen JM, Crochet D, Tijou I, Pacaud P, Loirand G. Drugeluting stents in bifurcations: bench study of strut deformation and coating lesions. Circ Cardiovasc Interv. 2010;3(2):120-6. 